\section{GÖDEL'S THEOREMS IN ENGLISH}

On Formally Undecidable Propositions of Principia Mathematica and Related Systems

By Kurt Gödel. Translated by Dr. B. Meltzer. Pp. viii + 72. (Edinburgh and London: Oliver and Boyd, Ltd., 1963.) 12s. 6d. net.

$\mathrm{T}$ HE appearance of this slender manual, possessing an importance out of all proportion to its slight build, is a major event in the field of meta-mathematics. Kurt Gödel announced his discovery to the Vienna Academy of Sciences in 1930, and publishod it in the Monatsheften für Mathematik und Physik, 38, Leipzig (1931). This contribution carried the somewhat involved title, translated into English, which forms that of the present book. In support of the English rendering of the original German, we are provided with an introduction by Prof R. B. Braithwaite, which is in the nature of a commentary and paraphrase combined. Its presenco adds greatly to the value of the transliteration, and is in itself a noteworthy addition to the literature of the subject. Taken together, therefore, the student of mathematica. logic can have before him everything that is essential to a grasp of what competent judges are inclined to regard as the most important discovery in this sphere of learning since the time of Aristotle.

This being so, the aim of a reviewer is presumably two-fold: to examine Dr. Meltzer's translation, and to offer one or two observations on the introduction. With regard to the former, the altogether admirable practice has been adopted of giving marginal page numbers (in square brackets) throughout the text of the original paper. Taking advantage of this, it has been easy quickly to compare the German and English at several crucial points, and the reader can rest assured of how accurately the task has been accomplished. And not only so; Gödel's theorems-there are really two-are works of art as well as of science, and the æsthetic content remains invariant. As occasionally happens, English is sometimes the neater. For example, the phrase ' $\omega$-consistent' is fundamentally an improvement over ' $\omega$-widerspruchfrein', and it only remains to notice that (as indicated on p. 34) $c$ is used from p. 57 onwards in place of Gödel's $x$, for class.

To turn to more general matters, and to Prof. Braithwaite's introduction in particular, Gödel's major discovery was to the effect that "every system of arithmetic contains arithmetical propositions concerned solely with relations between whole numbers which can neither be proved or disproved within the system". This statement shows the universality of Gödel's theorem compared with, say, Presburger's work of 1930, in which he established a decision procedure for an arithmetic restricted to addition, and excluding multiplication. In proposition XI (p. 70), Gödel states his Unprovability-of-Consistency theorem for a system $P$ as follows. "If $c$ be a given recursive consistent class of formula, then the propositional formula which states that $c$ is consistent is not c-provable." Alternatively, in Braithwaite's simplified form (class $c$ being null)-"If the formal system $P$ is consistent, its consistency is unprovable within $\mathrm{P}$ ". Gödel intonded to develop this further in Part 2, which has never been published.

The power and depth of Gödel's theorems are immense, and the introduction brings out these unique qualities, an achievement of the human mind perhaps without parallel in the modorn discipline of the meta-scionces, and a product, historically spoaking, of the Vienna Circle, disbanded before the Second World War.

At this stage we can be quite clear as to what Gödel accomplished, after which the attendant methodology becomes apparent. He showed how it was possible to construct a formula to convey the mathematical precept t hat the formula is not demonstrable, and established that this formula is demonstrable if, and only if, its negation is demonstrable. Next, though this formula is not formally demonstrable, it is nevertheless a true arithmetical formula. Lastly, this formula boing true and undemonstrable, the axioms of arithmetic are incomplete. This, in short, is the structure of the whole grand edifice.

Finally, for the methodology of this truly remarkable process of reasoning, Prof. Brathwaite's discussion is briefly as follows. Whitehead and Russell's Principia Mathematica forms a deductive system (which includes arithmetic), operating with a limited number of rules of inference. In order, however, to show that these rules will result in every theorem following from the axioms, one must consider the formuloe in the light of what Gödel calls 'mechanical rules' by obeying which another formula can be obtained by symbolic manipulation. There is therefore a certain correspondence between such a calculus and the deductive system. Gödel succeeded in mapping statoments 'about' arithmetic as expressions 'in' arithmetic, not unlike the method of Descartes in his algebraic geomotry. Syntactically, Gödel's theorem amounts to the discovery that arithmetic is basically, and in its very nature, incomplete.

Scholars owe a debt of gratitude to the Edinburgh Philosophy of Science Group which stimulated the trans lator to undertake the work of making these great advances in meta-theory available to English-speaking readers.

F. I. G. Rawlins

\section{GEOPHYSICS OF THE ATMOSPHERE}

\section{Exploring the Atmosphere}

By Dr. G. M. B. Dobson. Pp. $x+188$. (Oxford: Clarendon Press; London: Oxford University Press, 1963.) 21s. net.

$\mathrm{D}$

. G. M. B. DOBSON, who until recently was reader in meteorology in the University of Oxford, is well known for his investigations into the upper atmosphere and especially for his measurements and studies of ozone. This book, he tells us, was written because audiences at semi-popular lectures given during the International Geophysical Year had, in their questions, expressed a need for non-specialist books on geophysical subjects. The result is a small volume that surveys the whole scene, from sea-level through the troposphere, stratosphere and ionosphere to the fringes of the atmosphere, the regions of aurora, airglow and the radiation belts.

In the opening chapters, Dr. Dobson discusses, among other things, one of the historic problems of meteorology -why the temperature of the air first falls with height, then becomes constant, then rises and falls again and. finally, rises once more. The discussion covers not only direct measurements by radiosondes and rockets but also the earlier (and in some respects more fascinating) indirect deductions of high upper-air temperatures from observations of meteor trails and the anomalous propagation of sound. Then follow chapters on precipitation mechanisms and thunderstorms, and a clear and succinct account of the subject that Dr. Dobson has made his own, the origin, maintenance and distribution of atmospheric ozone. The accounts of ionospheric physics, aurora, airglow and the Van Allen radiation belts are preceded by a short chapter on the Sun, and the book concludes with a description of the Earth's magnetic field and its influence on the high atmosphere.

To cover such a wide range of topics in a book of less than two hundred pages without making it a mere catalogue of phenomena is something of a feat. Very wisely, the author has resisted the temptation to include and explain everything. It is not a connected account of the atmosphere but a collection of essays on some of 